\title{
Hydrogenotrophic Methanogenesis Under Alkaline Conditions
}

OPEN ACCESS

Edited by:

Ricardo Amils,

Autonomous University of Madrid,

Spain

Reviewed by:

Jose Luis,

Autonomous University of Madrid,

Spain

Xiuzhu Dong,

Chinese Academy of Sciences, China

*Correspondence:

Paul N. Humphreys

p.n.humphreys@hud.ac.uk

Specialty section:

This article was submitted to

Extreme Microbiology,

a section of the journal

Frontiers in Microbiology

Received: 05 October 2020 Accepted: 11 November 2020

Published: 03 December 2020

Citation:

Wormald RM, Rout SP, Mayes W, Gomes H and Humphreys PN (2020)

Hydrogenotrophic Methanogenesis Under Alkaline Conditions.

Front. Microbiol. 11:614227.

doi: 10.3389/fmicb.2020.614227
Richard M. Wormald ${ }^{1}$, Simon P. Rout ${ }^{1}$, William Mayes ${ }^{2}$, Helena Gomes ${ }^{2,3}$ and Paul N. Humphreys ${ }^{1 *}$

'Department of Biological and Geographical Sciences, University of Huddersfield, Huddersfield, United Kingdom, ${ }^{2}$ Department of Geography, Geology and Environment, University of Hull, Hull, United Kingdom, ${ }^{3}$ Food, Water, Waste Research Group, Faculty of Engineering, University of Nottingham, Nottingham, United Kingdom

A cement-based geological disposal facility (GDF) is one potential option for the disposal of intermediate level radioactive wastes. The presence of both organic and metallic materials within a GDF provides the opportunity for both acetoclastic and hydrogenotrophic methanogenesis. However, for these processes to proceed, they need to adapt to the alkaline environment generated by the cementitious materials employed in backfilling and construction. Within the present study, a range of alkaline and neutral $\mathrm{pH}$ sediments were investigated to determine the upper $\mathrm{pH}$ limit and the preferred route of methane generation. In all cases, the acetoclastic route did not proceed above pH 9.0, and the hydrogenotrophic route dominated methane generation under alkaline conditions. In some alkaline sediments, acetate metabolism was coupled to hydrogenotrophic methanogenesis via syntrophic acetate oxidation, which was confirmed through inhibition studies employing fluoromethane. The absence of acetoclastic methanogenesis at alkaline $\mathrm{pH}$ values (>pH 9.0) is attributed to the dominance of the acetate anion over the uncharged, undissociated acid. Under these conditions, acetoclastic methanogens require an active transport system to access their substrate. The data indicate that hydrogenotrophic methanogenesis is the dominant methanogenic pathway under alkaline conditions (>pH 9.0).

Keywords: alkaliphiles, radioactive waste, hydrogenotrophic methanogens, acetoclastic methanogens, alkaline

\section{INTRODUCTION}

Globally, geological disposal is largely the preferred choice for the management of intermediate level radioactive wastes (ILWs; IAEA, 2011) with a number of countries pursuing the establishment of geological disposal facilities (GDFs; Faybishenko et al., 2016). The exact design of these facilities is dependent on the host geology; however, there are often a number of common features, including the use of cementitious construction and backfill materials, the presence of metal in the construction, container and waste components, and organic, primarily cellulose, containing wastes.

The presence of metallic and organic materials means that abiotic and biotic gas generating processes (NEA, 2014) are likely to proceed within a GDF resulting in gas generation being evaluated in a number of international waste management programs (Felicione et al., 2003; NDA, 2010; Avis et al., 2011; Summerling, 2013; Poller et al., 2016). The anaerobic corrosion of metals will generate molecular hydrogen (NDA, 2010; Libert et al., 2011), which can in 
turn, act as an electron donor for hydrogenotrophic methanogenesis (Libert et al., 2011; Bagnoud et al., 2016). The alkaline conditions generated by the cementitious materials will promote the alkaline hydrolysis of cellulosic wastes (Humphreys et al., 2010). This abiotic process generates a range of cellulose degradation products (CDPs; Rout et al., 2015b; Charles et al., 2019) collectively which are dominated (>70\%) by isosaccharinic acids (ISAs; Almond et al., 2012).

Recent research has focused on the use of lime kiln waste sites to provide an insight into the biodegradation of CDP components under alkaline conditions (Milodowski et al., 2013; Charles et al., 2019). Despite the harsh geochemical environment ( $\mathrm{pH}>10.0)$, these sites support extensive and diverse bacterial and archaeal populations (Burke et al., 2012; Kyeremeh et al., 2016) capable of a wide range of metabolic and energy generating processes (Bassil et al., 2014; Rout et al., 2014, 2015a,b), including methanogenesis (Rout et al., 2015b). The information that is available for these sites suggests that the hydrogenotrophs dominate the methanogenic populations despite the availability of acetic acid and the absence of competition by other acetate consuming pathways (Charles et al., 2015; Rout et al., 2015b; Kyeremeh et al., 2016).

Given the importance of methanogenesis to gas generation within a GDF, a range of anthropogenic alkaline environments of various ages were investigated to determine the impact of environmental $\mathrm{pH}$ on the nature and extent of methanogenic activity.

\section{MATERIALS AND METHODS}

\section{Sampling Site Investigations}

The investigation involved sediments from three lime kiln waste sites $(\approx 25$ to $\approx 150$ years old; New Lime sites, designated $\mathrm{B}, \mathrm{H}$, and T; Charles et al., 2019), five field kiln sites (Johnson, 2008; 200-300 years old; Old Lime sites, designated LK1, LK2, LK3, LK4, and LK5), and four steel industry waste sites ( 5 to $\approx 30$ years old; Mayes et al., 2008; Steel sites, designated CW, CS, RC, and $\mathrm{SC}$; see Supporting Information). In addition, a neutral $\mathrm{pH}$, freshwater anaerobic sediment was employed as a control (Control). In the case of the New Lime, Steel, and Control sites, hand cored samples (dia. $30 \mathrm{~mm})$ were taken at depth $(\sim 1 \mathrm{~m})$. In the case of the Old Lime sites, samples were taken from a shallow depth of $10-30 \mathrm{~cm}$ using a stainless steel trowel. All sampling equipment was surface sterilize using a commercial hypochlorous acid spray (Redditch Medical Ltd., Stockton on Tees, UK). Sterile plastic sample containers were filled to maximum capacity with sediments and where possible with the associated pore waters in order to minimize the presence of oxygen. The $\mathrm{pH}$ values of the associated pore waters were determined in situ with a hand-held $\mathrm{pH}$ probe (Mettler Toledo, Columbus, $\mathrm{OH}$, Unites States) and the $\mathrm{pH}$ of the soil/sediment determined using standard methods (B.S.I, 2005).

\section{Microcosm Investigations}

All microcosms employed in the study were incubated in the dark at $25^{\circ} \mathrm{C}$, and the incubation time was dependent on the time taken for the microcosm to generate detectable methane and ranged from 2 to 8 weeks. Initial microcosms employing New Lime and Control sediments were established by mixing a soil/sediment sample (5 g) from each location with $5 \mathrm{ml}$ of sterile, nitrogen purged mineral media (MM; Supplementary Tables S1, S2; B.S.I, 2005) adjusted to $\mathrm{pH}$ 10.0 with $4 \mathrm{M} \mathrm{NaOH}$ for New Lime microcosms and $\mathrm{pH} 7.0$ for the Control microcosms. Slurries were then transferred to $100 \mathrm{ml}$ crimp top bottles containing $100 \mathrm{ml}$ of MM supplemented with 10\% v/v CDP and a hydrogen:nitrogen (10:90) headspace (BOC Ltd., Guildford, UK). A CDP/hydrogen enrichment was chosen since this had previously been shown (Rout et al., 2014, 2015a; Kyeremeh et al., 2016) to support a diverse range of microbial processes and provided a source of fermentable substrates, acetate, and hydrogen. CDP was prepared as previously described (Rout et al., 2014, 2015a) All microcosm experiments were carried out in duplicate.

On the detection of methane initial enrichments were sub-cultured twice at the starting $\mathrm{pH}$ by inoculating sterile microcosms with $5 \mathrm{ml}$ of the previous microcosm suspension (Supplementary Figure S1). This was carried out to reduce the impact of residual fermentable substrates, mineral components, and other electron acceptors [e.g., Iron (III) and sulphate] present within the inoculating sediment.

Once methane generation was detected at the starting $\mathrm{pH}$, each sediment was sequentially exposed to a range of $\mathrm{pH}$ values ranging from 7.0 to 12.0 (Supplementary Figure S1) as described below. Every microcosm that was methane positive was sub-cultured at the next $\mathrm{pH}$ in the series and, hydrogen and acetate enrichments were created at the original $\mathrm{pH}$ (Supplementary Figure S1). The last $\mathrm{pH}$ in the series that failed to generate methane was still sub-cultured into hydrogen and acetate enrichments. These enrichments were performed by transferring $5 \mathrm{ml}$ of the microcosm suspension to a $100 \mathrm{ml}$ crimp top bottle containing $100 \mathrm{ml}$ of $\mathrm{MM}$ with either a hydrogen: carbon dioxide: nitrogen (10:10:80; BOC Ltd., Guildford, United Kingdom) headspace or MM supplemented with $\mathrm{Na}$-acetate $(30 \mathrm{mM})$ with a $100 \%$ nitrogen headspace. A set of blank microcosms were also established as described above with MM, soil, and a 100\% nitrogen atmosphere.

\section{Chemical Analysis}

Headspace hydrogen and methane was determined via an Agilent GC6850 equipped with HP-PLOT/Q column with particle traps $((35 \mathrm{~m} \times 0.32 \mathrm{~mm} \times 20 \mu \mathrm{m})$, Agilent Technologies, Santa Clara, CA, United States) employing thermal conductivity detection. Liquid microcosm samples $(1 \mathrm{ml})$ were also removed over the course of incubation using degassed syringes and needles. Acetic acid concentrations were determined using gas chromatography (Hewlett Packard Ltd., London, United Kingdom) with a flame Ionization detector (GC-FID) as described previously (Rout et al., 2015a). To determine the presence of acetoclastic methanogenesis the metabolic inhibitor methylflouride was employed at an initial concentration of $1 \%$ as described previously (Daebeler et al., 2013). Duplicate reactors without inhibitor addition were also prepared 
and served as a control. Methane produced from $\mathrm{CO}_{2}\left(\mathrm{~m}_{\mathrm{CO}_{2}}\right)$ was calculated from inhibited microcosms $002 \mathrm{C}$ and acetate-derived methane was calculated from methane production in uninhibited microcosms $\left(\mathrm{m}_{\text {acetate }}=\mathrm{m}_{\text {total }}-\mathrm{m}_{\mathrm{CO}_{2}}\right)$.

\section{$16 S$ rRNA Gene Sequencing}

Total genomic DNA was extracted from both soil/sediment samples and methanogenic enrichment cultures using the PowerSoil DNA Isolation Kit (Qiagen, Manchester, UK). The enrichment cultures were sampled after 2 weeks of incubation by the centrifugation $(10,000 \times g)$ of the microcosm fluid to pellet the cells prior to DNA extraction. The V4 region of the 16S rRNA gene was then amplified by PCR using primers $341 \mathrm{f}$ and $805 \mathrm{r}$ (Takahashi et al., 2014). Next generation sequencing of PCR products was carried out by ChunLab (South Korea) using the Illumina MiSeq platform. Sequences were then paired and clustered into OTUs using DADA2 employing R3.2.5 (Callahan et al., 2016), before being identified using the MegaBLAST search strategies (Altschul et al., 1997).

\section{RESULTS}

\section{CDP Fed NEW Lime Microcosms}

Within microcosms utilizing CDP as a carbon source, the Control enrichments demonstrated a linear reduction in methane production between $\mathrm{pH} 7.0$ and 11.0 (Figure 1), while the New Lime enrichments demonstrated an optimum $\mathrm{pH}$ of 9.0 for methane generation and a linear reduction down to $\mathrm{pH}$ 12.0. This optimum is below the in-situ $\mathrm{pH}$ of the New Lime sites ( $\mathrm{pH}$ 11.5-13.0, Supplementary Table S3), suggesting that the in-situ populations have alternative strategies to manage these harsh $\mathrm{pH}$ values (Charles et al., 2017).

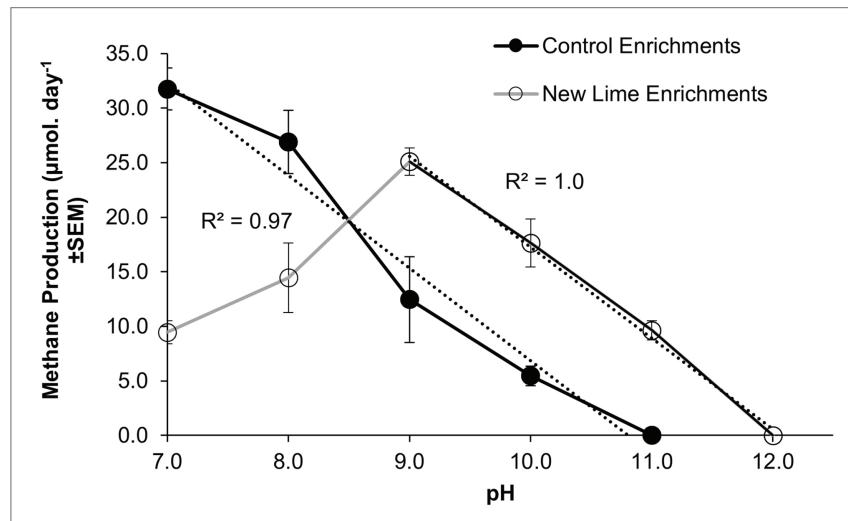

FIGURE 1 | Methane production rates in CDP-fed microcosms employing Control and New Lime sediments operating between $\mathrm{pH} 7.0$ and 12.0. Control microcosms ( $n=2$ at all pH values) had a pH optimum of $7.0(n=3)$, in contrast to the New Lime microcosms $(n=2 \mathrm{pH} 7.0, n=4 \mathrm{pH} 8.0, n=6$

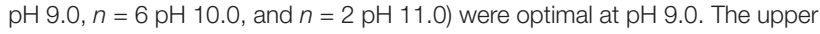
$\mathrm{pH}$ limit for methanogenesis was $\mathrm{pH} 10.0$ for the Control sediment, and this increased to $\mathrm{pH} 11.0$ in the case of the New Lime sediments. No methane generation was detected at a $\mathrm{pH}>11.0$ (" $n$ " denotes the number of replicates analyzed)
Mean methane production values for those microcosms producing methane are presented (Figure 1) in order to emphasize the overall trends observed. Across the $\mathrm{pH}$ range investigated the microbial populations enriched from the three New Lime sites demonstrated different responses to changing $\mathrm{pH}$ with the oldest site (site B; see Supplementary Material) generating methane across the whole range and the other two sites generating methane across narrower $\mathrm{pH}$ ranges (Supplementary Figure S2).

In the Control sediment enrichments, the archaeal community composition was composed of almost equal proportions of acetoclastic to hydrogenotrophic methanogens (46:54\%; Figure 2) at $\mathrm{pH} 7.0$ and 8.0. As the enrichment $\mathrm{pH}$ became more alkaline $(\mathrm{pH} \geq 9.0)$, the community composition shifted toward a more hydrogenotrophic population Figure $\mathbf{2}$ even though acetate was present in these cultures. The New Lime sediment enrichments were dominated by hydrogenotrophic methanogens (Figure 2), suggesting that the long-term exposure to alkaline $\mathrm{pH}$ had selected against acetoclastic methanogens in these sediments.

\section{$\mathrm{H}_{2}: \mathrm{CO}_{2}$ and Acetate Fed New Lime microcosms}

The trend toward hydrogenotrophic methanogenesis at alkaline $\mathrm{pH}$ was confirmed by the establishement of hydrogen and acetate enrichments from the CDP fed Control and New Lime enrichments at each $\mathrm{pH}$. Within the $\mathrm{H}_{2}: \mathrm{CO}_{2}$ Control sediment enrichments, hydrogen consumption was at its highest at $\mathrm{pH}$ 7.0 at $243.3 \mu \mathrm{mol} \mathrm{day}{ }^{-1}$, and became undetectable as $\mathrm{pH}$ increased to $\mathrm{pH} 11.0$ (Figure 3A). The associated methanogenic communities were most diverse at $\mathrm{pH} 7.0$ with 12 different methanogenic genera detected (Figure 3B). Methanobacterium spp. were the most dominant at this $\mathrm{pH}$, comprising $60.7 \%$ of the community; with Methanoregula spp. (14.7\%) and Methanosphaerula spp. (10.2\%) also being prevalent within the community. As $\mathrm{pH}$ was increased through to $\mathrm{pH} 10.0$, the loss of a number of the genera observed at $\mathrm{pH} 7.0$ coincided with the further dominance of Methanobacterium spp., rising to $97.1 \%$ of the community at $\mathrm{pH} 10.0$.

These findings were reinforced by the $\mathrm{H}_{2}: \mathrm{CO}_{2}$ New Lime enrichments in which Methanobacterium spp. were the dominant taxa detected across all pH (7.0-11.0) enrichments (Figure 3B). A negative relationship between hydrogen consumption and increasing $\mathrm{pH}$ was seen in these enrichments as $\mathrm{pH}$ decreased for $\mathrm{pH}$ 9.0-11.0, however hydrogen consumption was still detected at $\mathrm{pH} 11.0\left(77.0 \mu \mathrm{mol} \mathrm{day}{ }^{-1}\right)$. The optimum $\mathrm{pH}$ for hydrogenotrophic methanogenesis was $\mathrm{pH} 9.0$ with a hydrogen consumption of $167.5 \mu \mathrm{mol} \mathrm{day}{ }^{-1}$. The alkaliphilic nature of the methanogenic population in the New Lime sediments was indicated by the fact that the rates of hydrogen metabolism decreased as the $\mathrm{pH}$ fell below $\mathrm{pH} 9.0$ (Figure 3A). The data here reiterate that the optimum $\mathrm{pH}$ for hydrogenotrophic methanogenesis is $\mathrm{pH} 9.0$ for communities of this type, and that it is not the availability of substrate from fermentation (such as CDP) that is a limiting factor. As was the case with the CDP reactors, not all the New Lime enrichments were active across the whole $\mathrm{pH}$ range (Supplementary Figure S3). 


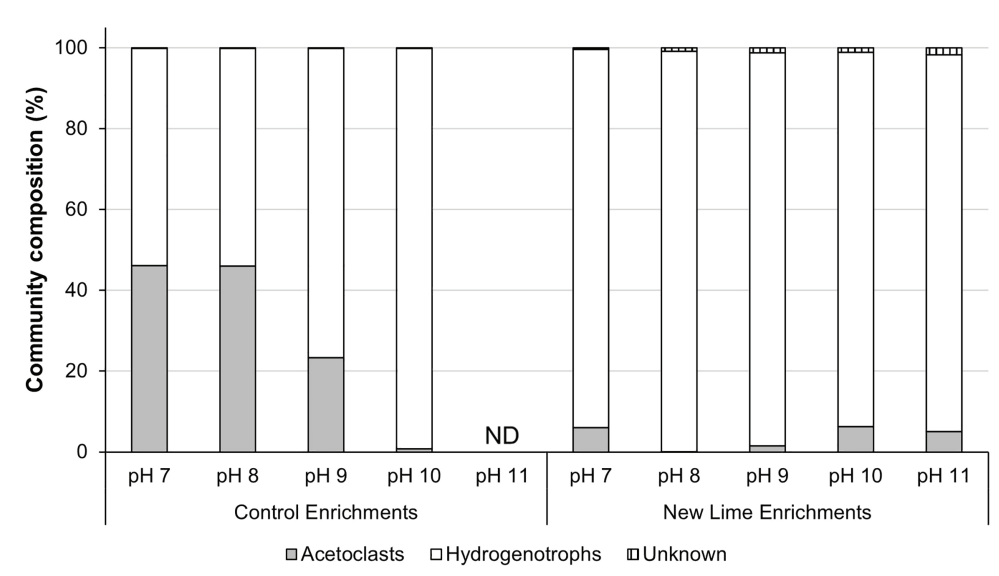

FIGURE 2 | Methanogen communities in neutral and alkaline soil enrichments. When the neutral pH Control sediment was enriched with CDP the acetoclastic and hydrogenotrophic communities were present in roughly equal proportions at $\mathrm{pH} 7.0$ and 8.0, respectively. As the pH increased to $\mathrm{pH} 10.0$, the acetoclastic compostion fell as $\mathrm{pH}$ increased, with no methanogen community detectable at $\mathrm{pH}$ 11.0. In contrast the alkaline New Lime enrichments were dominated by hydrogenotrophic methanogens irrespective of enrichment $\mathrm{pH}$ (ND, none determined).

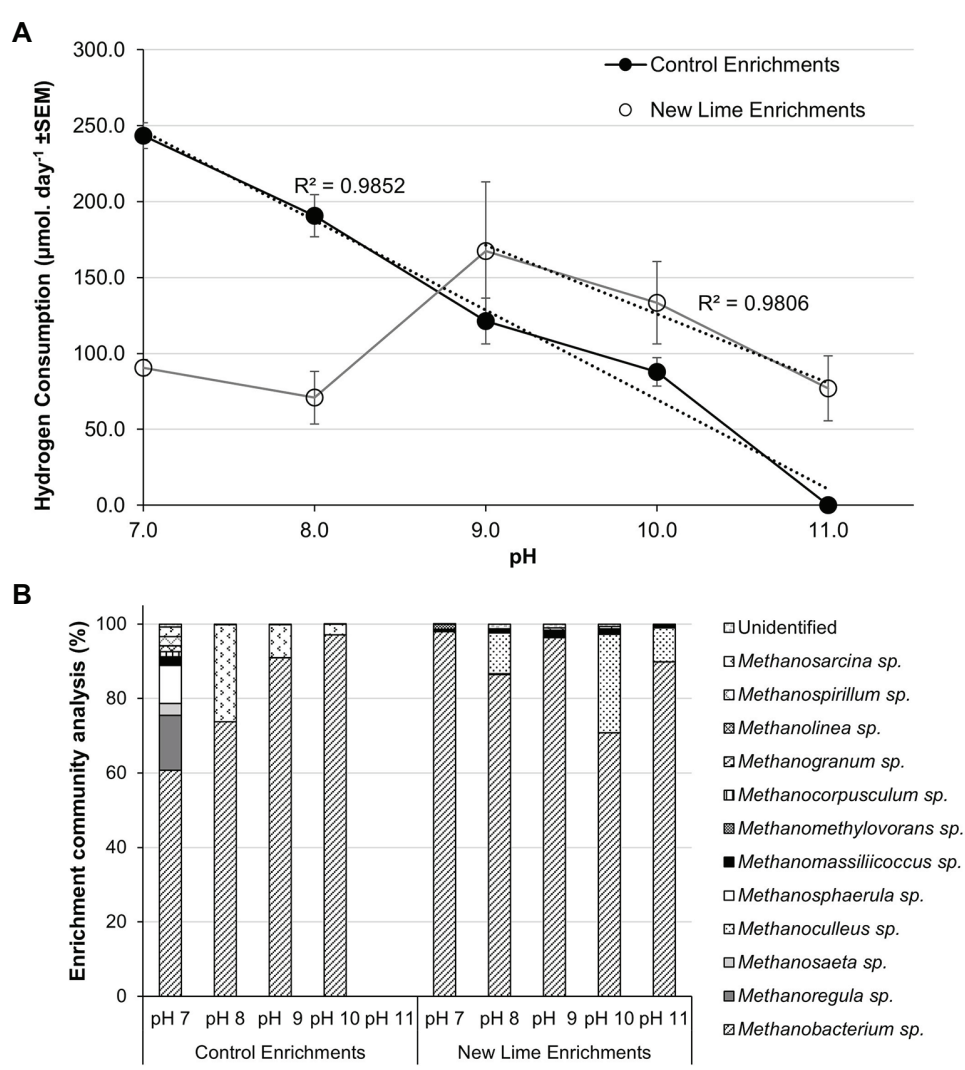

FIGURE 3 | Hydrogen consumption rates (A) and methanogen populations $\mathbf{( B )}$ in $\mathrm{H}_{2} / \mathrm{CO}_{2}$ enriched microcosms from Control $(n=2)$ and New Lime $(n=6)$ soils. An increasing pH negatively impacted upon hydrogen consumption in Control soil enrichments ( $n=2$ at all pH values), while New Lime sediments $(n=4 \mathrm{pH} 7.0, n=4$ $\mathrm{pH}$ 8.0, $n=6 \mathrm{pH}$ 9.0, $n=6 \mathrm{pH}$ 10.0, $n=4 \mathrm{pH}$ 11.0) demonstrated an optimum pH of 9.0. Across all enrichments, Methanobacterium sp. were the dominant genus. $\mathrm{ND}$, none detected (" $n$ " denotes the number of replicates analyzed).

Acetate fed control enrichments contained both acetoclastic and hydrogenotrophic methanogens (Figure 4B). Hydrogenotrophic methanogens are able to generate methane from acetate via syntrophic acetate oxidation (SAO). SAO is an endergonic reaction with a Gibbs free energy of $+104.6 \mathrm{~kJ} \mathrm{~mol}^{-1}$ and is, therefore, energetically less favorable 
than acetoclastic methanogenesis; however, when the oxidation of acetate is coupled to hydrogenotrophic methanogenesis, the total combined reaction is exergonic $\left(\Delta \mathrm{G} 0^{\prime}=-31 \mathrm{~kJ} \mathrm{~mol}^{-1}\right.$; Hattori, 2008). Few SAO bacteria have been described, but $\mathrm{SAO}$ is associated with the members of the phylum Firmicutes (Hattori et al., 2000; Balk et al., 2002; Westerholm et al., 2010; Manzoor et al., 2018). In the acetate fed Control enrichments (Figure 4A), a linear reduction $\left(\mathrm{R}^{2}=0.97\right)$ in the rate of acetate removal was observed between $\mathrm{pH} 7.0$ and 9.0 from 182.7 to $33.7 \mu$ moles day ${ }^{-1}$; with a cessation of activity at $\mathrm{pH}$ 10.0. Methanosarcina spp. contributed $65.1 \%$ of the $\mathrm{pH} 7.0$ and $79.3 \%$ of the $\mathrm{pH} 8.0$ Control enrichment populations (Figure 4B). This fell to $7.1 \%$ within the $\mathrm{pH} 9.0$ enrichment. The fall in acetate consumption between $\mathrm{pH} 7.0$ and 8.0 coincided with the loss of both Methanospirillium and Methanosaeta spp. and a reduced proportion of Methanosarcina between $\mathrm{pH} 8.0$ and 9.0. The loss of Methanospirillium spp. may suggest that $\mathrm{SAO}$ was active at $\mathrm{pH} 7.0$ in these systems but was not able to adjust to the increase in $\mathrm{pH}$.

Low levels of acetate consumption were only observed at both pH $8.0\left(36.4 \mu\right.$ moles day $\left.{ }^{-1}\right)$ and $\mathrm{pH} 7.0\left(23.6 \mu\right.$ moles day $\left.{ }^{-1}\right)$ in acetate enrichments from two of the three New Lime sites. However, the methanogenic populations in these enrichments were dominated by the hydrogenotrophic (Liu and Whitman, 2008; Dridi et al., 2012) Methanobacterium, Methanoculleus, and Methanomassiliicossus spp., with the potentially acetoclastic Methanosarcina spp. representing only $1.2 \%$ of the total archaeal populations at these $\mathrm{pH}$ values (Figure 4B). However, the members of the phylum Firmicutes which comprised $30-40 \%$ of the total populations of the $\mathrm{pH} 8.0$ and $7.0 \mathrm{New}$ Lime acetate enrichments, suggesting that SAO may be responsible for the low levels of acetate removal in these enrichments.

\section{Inhibition Studies}

To investigate the role of in the acetate fed enrichments, the pH 7.0 acetate fed New Lime enrichments were sub-cultured in the presence of acetate and fluoromethane, an inhibitor of acetoclastic methanogenesis (Agneessens et al., 2018). Within these enrichments (Supplementary Figure S4), acetate removal was observed in both the presence and absence of inhibitor (removal rates: presence: $4.1 \times 10^{-2} \pm 4 \times 10^{-3} \mathrm{mmol} \mathrm{day}^{-1}$; absence: $3.5 \times 10^{-2} \pm 4 \times 10^{-3} \mathrm{mmol} \mathrm{day}^{-1}$ ), suggesting that acetate removal in these sediments was SAO linked. The addition of fluoromethane to $\mathrm{pH} 7.0$ acetate fed Control enrichment saw a cessation of acetate removal, indicating that in this case, acetoclastic methanogens was the dominant acetate removal

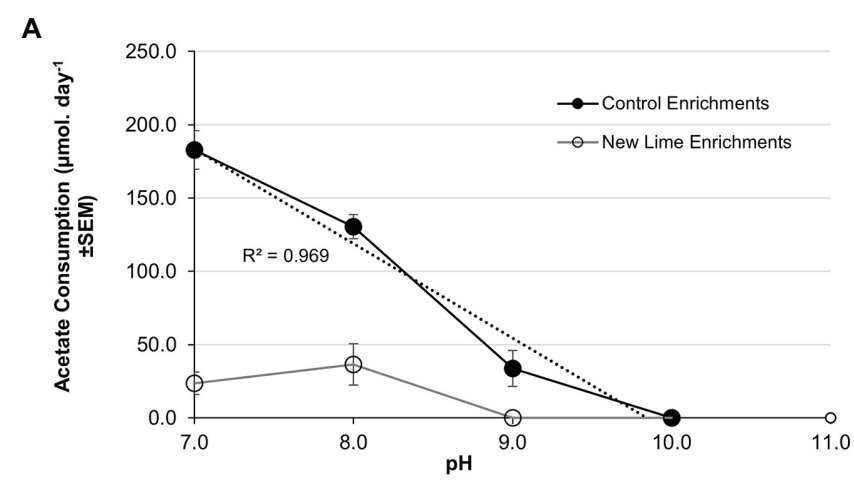

B

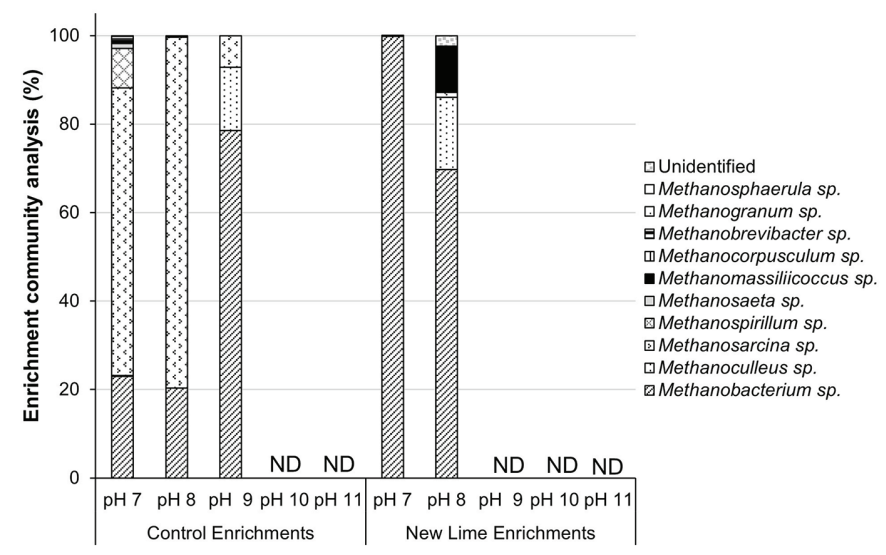

FIGURE 4 | Acetate consumption rates (A) and methanogen populations (B) in sodium acetate enriched microcosms from Control and New lime soils. Increasing $\mathrm{pH}$ negatively impacted upon acetate consumption with no acetate consumption observed above pH 9.0 in either the Control $(n=2$ at all pH values) enrichments or the New Lime enrichments ( $n=2 \mathrm{pH} 7.0, n=2 \mathrm{pH}$ 8.0). Methanosarcina spp. and Methanobacterium spp. were the dominant genera in Control enrichments while Methanobacterium sp. were dominant in the New Lime enrichments. ND, none detected (" $n$ " denotes the number of replicates analyzed). 
process even though the presence of hydrogenotrophs such as Methanospirillium spp. may suggest some SAO activities (Supplementary Figure S5). These results suggest that the role of SAO in methanogen generation in alkaline environments warrants further study.

\section{Steel and Old Lime Microcosms at pH 7 and 10}

In order to determine the extent to which alkaline $\mathrm{pH}$ impacts upon acetoclastic methanogenesis across a wider selection of anthropogenic alkaline environments with more diverse methanogenic populations, sediments from the Steel and Old Lime sites were used to establish microcosms at $\mathrm{pH} 7.0$ and 10.0. The Old Lime sediments $(n=5)$ had in-situ $\mathrm{pH}$ values closer to circum-neutral $\mathrm{pH}$ values, suggesting that the bulk environment had recovered from exposure to alkaline contamination. However, lime fragments are likely to be present within these sediments, suggesting that alkaline microsites will persist. The enrichments from these sediments were similar to the Control sediments, with both acetate and hydrogen consumptions being negatively impacted by an increase in $\mathrm{pH}$ from $\mathrm{pH} 7.0$ to 10.0 (Figure 5). In particular, no acetate consumption or methane production was observed at $\mathrm{pH}$ 10.0. The acetate consumption rates at $\mathrm{pH} 7.0$ were $2.0 \times 10^{-2}$ $\left( \pm 7.7 \times 10^{-3}\right)$ day $^{-1}$ and this coincided with the detection of Methanoculleus sp. (70.5\%), Methanosarcina sp. (16.6\%), and Methanomasiliicoccus sp. (11.6\%). Hydrogen consumption could still be detected within the $\mathrm{pH} 10.0$ enrichments; however, the rate fell from that observed at $\mathrm{pH} 7.0\left[43.1( \pm 6.4) \mu \mathrm{mol} \mathrm{day}^{-1}\right]$ to $17.4( \pm 4.6) \mu \mathrm{mol} \mathrm{day}{ }^{-1}$. At both $\mathrm{pH} 7.0$ and 10.0, Methanoculleus sp. dominated the community composition, representing 61.6 and $89.8 \%$ of the communities, respectively.

The $\mathrm{pH}$ of the Steel sediments ranged from $\mathrm{pH} 9.5$ to 12.9. The enrichment of these sediments with either acetate or $\mathrm{H}_{2}: \mathrm{CO}_{2}$ demonstrated similar behavior to that observed with the New
Lime sediments, again no acetate consumption was detected at $\mathrm{pH} 10.0$ but was observed at $\mathrm{pH} 7.0$ with a rate of 36.5 $( \pm 2.0) \mu \mathrm{mol} \mathrm{day}{ }^{-1}$. At $\mathrm{pH} 7.0$, acetoclastic communities from the Steel sites were dominated by Methanosarcina sp. (78.8\%) with Methanobacterium sp. comprising $20.6 \%$ of the community. In contrast to the New Lime enrichments (Figure 3A), the Steel site sediments (Figure 5) demonstrated a greater rate of hydrogen consumption at $\mathrm{pH} 7.0\left(90.8 \pm 1.9 \mu \mathrm{mol} \mathrm{day}^{-1}\right)$ than at $\mathrm{pH} 10.0\left(85.1 \pm 3.2 \mu \mathrm{mol} \mathrm{day}{ }^{-1}\right)$, although these were not significantly different $(p=0.105)$. The hydrogenotrophic methanogenic microcosms were again dominated by Methanobacterium sp.

Overall the results indicate that hydrogenotrophic methanogenesis is favored over acetoclastic methanogenesis at alkaline $\mathrm{pH}(>9.0)$. This observation is consistent across a wide range of calcium based anthropogenic sites of different origins and ages. Under the prevailing geochemical conditions created at these $\mathrm{pH}$ values the acetoclastic methanogenic pathway is unable to access its substrate due to the absence of undissociated acetic acid at these $\mathrm{pH}$ values.

\section{DISCUSSION}

The data presented here suggest that an alkaline $\mathrm{pH}>9.0$ results in a methanogen community that is dominated by hydrogenotrophs, with populations enhanced by the activity of SAO bacteria. The methanogen populations from high $\mathrm{pH}$ and neutral sediments exposed to alkaline $\mathrm{pH}$ were both dominated by Methanobacterium sp., and in the case of the New Lime sediment communities, were capable of hydrogenotrophic methanogenesis at $\mathrm{pH}$ 11.0. Members of the Methanobacteriales have also been detected within a range of hyperalkaline environments resulting from serpentinisation processes (Brazelton et al., 2017; Crespo-Medina et al., 2017).

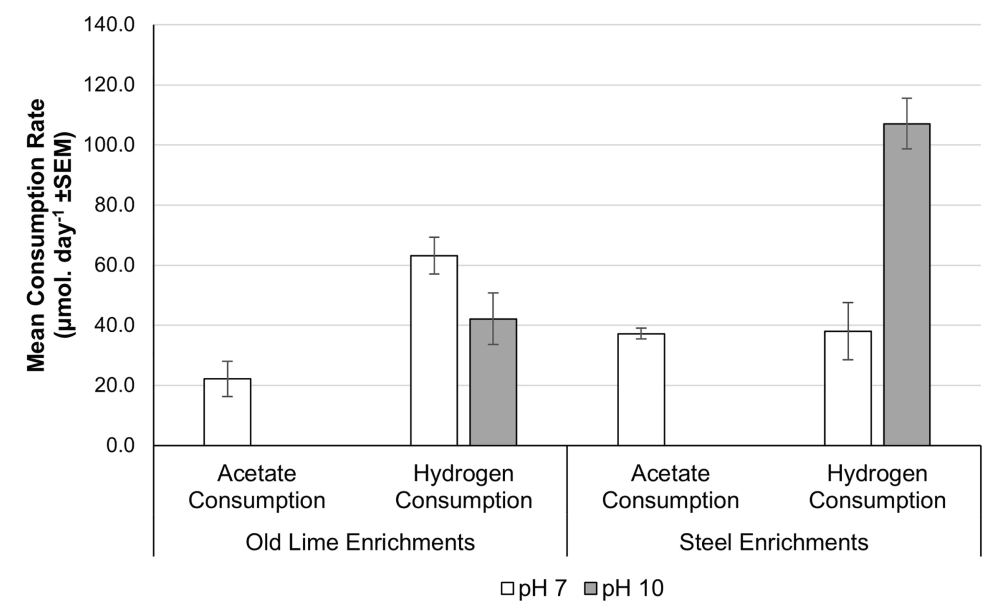

FIGURE 5 | Acetate and hydrogen consumption from microcosms prepared using Old Lime and Steel site sediments as an enrichment inoculum. The pattern observed in the Old Lime $(n=10)$ and Steel $(n=8)$ sediments mirrored that seen with the New Lime and Control sediments with acetoclastic methanogenesis absent at alkaline $\mathrm{pH}$ (" $n$ " denotes the number of replicates analyzed). 
A number of alkaliphilic Methanobacterium sp. have been isolated to date (Boone et al., 1986; Mathrani et al., 1988; Kotelnikova et al., 1998), the observations made here suggest that this genus is adaptable to aggressive $\mathrm{pH}$ changes as observed with Control sediment enrichments, but is also capable of surviving high $\mathrm{pH}$ after long-term exposure as residents of the initial New Lime sediments. This is in contrast to the Methanomicrobiales such as Methanocalculus sp. which are more prevalent in the hypersaline-hyperalkaline Soda lakes (Surakasi et al., 2007; Antony et al., 2013; Sorokin et al., 2015), due to the low salt tolerance of Methanobacterium sp. (Boone et al., 1986). In this study, Methanosarcina sp. were most impacted in the control sediments exposed to high $\mathrm{pH}$ in acetate enrichments. Pure culture studies of Lonar lake Methanosarcina indicated a maximum $\mathrm{pH}$ of 9.5 for growth upon acetate (Thakker and Ranade, 2002), which suggests that this genus may require a saline rather than a calcium dominated environment to sustain methane generation above $\mathrm{pH}$ 9.0.

These observations indicate that the generation of methane through the acetoclastic pathway, although energetically favorable with respect to bicarbonate (Jin and Kirk, 2018) does not proceed under alkaline conditions $(>\mathrm{pH} 9.0)$. High $\mathrm{pH}$ favors the dissociation of acetic acid to its anion $\left(\mathrm{CH}_{3} \mathrm{COO}^{-}\right)$, preventing transmembrane diffusion (Kröninger et al., 2014). Under alkaline conditions, acetate transport into the acetoclastic methanogen cell is therefore reliant on an acetate transporter, which is likely to be less energetically favorable than hydrogenotrophic methanogenesis (Kröninger et al., 2014). Much of the current understanding of methanogen ecology under alkaline conditions has been focused upon the microbiology of hypersaline, hyperalkaline Soda lakes, where methanogenesis is most commonly associated with the metabolism of C-1 compounds being released upon the biodegradation of Cyanobacterial mats (Jones et al., 1998; Sorokin et al., 2017). The current study indicates that methanogenesis in non-saline, calcium dominated alkaline environments should be considered as a different ecological niche. Within these environments, hydrogenotrophic methanogenesis is the most prevalent methanogenic pathway above $\mathrm{pH}$ 9.0. This observation is supported by the investigations of sediments from 13 individual sites ranging in age, origin and chemical composition. These observations suggest that under the alkaline conditions generated within a cement-based

\section{REFERENCES}

Agneessens, L. M., Ottosen, L. D. M., Andersen, M., Olesen, C. B., Feilberg, A., and Kofoed, M. V. W. (2018). Parameters affecting acetate concentrations during in-situ biological hydrogen methanation. Bioresour. Technol. 258, 33-40. doi: 10.1016/j.biortech.2018.02.102

Almond, M., Shaw, P. B., Humphreys, P. N., Chadha, M. J., Niemelä, K., and Laws, A. P. (2012). Behaviour of xyloisosaccharinic acid and xyloisosaccharino-1, 4-lactone in aqueous solutions at varying pHs. Carbohydr. Res. 363, 51-57. doi: 10.1016/j.carres.2012.09.019

Altschul, S. F., Madden, T. L., Schäffer, A. A., Zhang, J., Zhang, Z., Miller, W., et al. (1997). Gapped BLAST and PSI-BLAST: a new generation of protein database search programs. Nucleic Acids Res. 25, 3389-3402. doi: 10.1093/ nar/25.17.3389
GDF, it is the hydrogenotrophic methane generation pathway that will be active rather than acetoclastic methanogenesis.

\section{DATA AVAILABILITY STATEMENT}

The data is deposited with the NCBI under Bioproject accession number PRJNA525260.

\section{AUTHOR CONTRIBUTIONS}

$\mathrm{PH}, \mathrm{SR}, \mathrm{WM}$, and HG contributed to conception and design of the study. RW carried out the experimental work. PH, WM, HG, RW, and SR participated in the field work. SR, PH, and RW wrote the first draft. All authors contributed to manuscript revision, read, and approved the submitted version.

\section{FUNDING}

Richard Wormald's $\mathrm{PhD}$ was supported by a Radioactive Waste Management Ltd. (RWM) research bursary. RWM Ltd. is a wholly own subsidiary of the UK Nuclear Decommissioning Authority, a non-departmental public body which reports to the UK Department for Business, Energy, and Industrial Strategy. WM and HG were supported by the NERC R3AW grant (NE/ L014211/1).

\section{ACKNOWLEDGMENTS}

We would like to thank the following individuals and organizations. David Johnson for his assistance regarding the field kiln sites investigated. The Canal and River Boat Trust, Hanson Aggregates, Tarmac plc, Tee Valley Wildlife Trust and British Steel.

\section{SUPPLEMENTARY MATERIAL}

The Supplementary Material for this article can be found online at: https://www.frontiersin.org/articless/10.3389/fmicb.2020.614 227/full\#supplementary-material

Antony, C. P., Kumaresan, D., Hunger, S., Drake, H. L., Murrell, J. C., and Shouche, Y. S. (2013). Microbiology of Lonar Lake and other soda lakes. ISME 7, 468-476. doi: 10.1038/ismej.2012.137

Avis, J., Calder, N., Humphreys, P., King, F., Suckling, P., and Walsh, R. (2011). Postclosure Safety Assessment: Gas Modelling. Ontario, Canada: Nuclear Waste Management Organization.

B.S.I (2005). BS ISO 14853:2005 Plastics-Determination of the ultimate anaerobic biodegradation of plastic materials in an aqueous system- Method by measurement of biogas production. British Standards Institute, London, UK.

Bagnoud, A., Chourey, K., Hettich, R. L., de Bruijn, I., Andersson, A. F., Leupin, O. X., et al. (2016). Reconstructing a hydrogen-driven microbial metabolic network in Opalinus Clay rock. Nat. Commun. 7:12770. doi: 10.1038/ncomms12770

Balk, M., Weijma, J., and Stams, A. J. (2002). Thermotoga lettingae sp. nov., a novel thermophilic, methanol-degrading bacterium isolated from a thermophilic 
anaerobic reactor. Int. J. Syst. Evol. Microbiol. 52, 1361-1368. doi: 10.1099/00207713-52-4-1361

Bassil, N. M., Bryan, N., and Lloyd, J. R. (2014). Microbial degradation of isosaccharinic acid at high pH. ISME 9, 310-320. doi: 10.1038/ismej.2014.125

Boone, D. R., Worakit, S., Mathrani, I. M., and Mah, R. A. (1986). Alkaliphilic methanogens from high-pH lake sediments. Syst. Appl. Microbiol. 7, 230-234. doi: 10.1016/S0723-2020(86)80011-X

Brazelton, W. J., Thornton, C. N., Hyer, A., Twing, K. I., Longino, A. A., Lang, S. Q., et al. (2017). Metagenomic identification of active methanogens and methanotrophs in serpentinite springs of the Voltri Massif Italy. PeerJ 5:e2945. doi: 10.7717/peerj.2945

Burke, I., Mortimer, R., Palani, S., Whittleston, R., Lockwood, C., Ashley, D., et al. (2012). Biogeochemical reduction processes in a hyper-alkaline affected leachate soil profile. Geomicrobiol J. 29, 769-779. doi: 10.1080/01490451.2011.619638

Callahan, B. J., McMurdie, P. J., Rosen, M. J., Han, A. W., Johnson, A. J. A., and Holmes, S. P. (2016). DADA2: High resolution sample inference from Illumina amplicon data. Nat. Methods 13, 581-583. doi: 10.1038/nmeth.3869

Charles, C. J., Rout, S. P., Garratt, E. J., Patel, K., Laws, A. P., and Humphreys, P. N. (2015). The enrichment of an alkaliphilic biofilm consortia capable of the anaerobic degradation of isosaccharinic acid from cellulosic materials incubated within an anthropogenic, hyperalkaline environment. FEMS Microbiol. Ecol. 91:fiv085. doi: 10.1093/femsec/fiv085

Charles, C., Rout, S., Patel, K., Akbar, S., Laws, A., Jackson, B., et al. (2017). Floc formation reduces the $\mathrm{pH}$ stress experienced by microorganisms living in alkaline environments. Appl. Environ. Microbiol. 83, e02985-e02916. doi: 10.1128/AEM.02985-16

Charles, C. J., Rout, S. P., Wormald, R., Laws, A. P., Jackson, B. R., Boxall, S. A., et al. (2019). In-Situ Biofilm Formation in Hyper Alkaline Environments. Geomicrobiol J. 36, 404-411. doi: 10.1080/01490451.2018.1564803

Crespo-Medina, M., Twing, K. I., Sánchez-Murillo, R., Brazelton, W. J., McCollom, T. M., and Schrenk, M. O. (2017). Methane dynamics in a tropical serpentinizing environment: the Santa Elena Ophiolite, Costa Rica. Front. Microbiol. 8:916. doi: 10.3389/fmicb.2017.00916

Daebeler, A., Gansen, M., and Frenzel, P. (2013). Methyl fluoride affects methanogenesis rather than community composition of methanogenic archaea in a rice field soil. PLoS One 8:e53656. doi: 10.1371/journal.pone.0053656

Dridi, B., Fardeau, M. -L., Ollivier, B., Raoult, D., and Drancourt, M. J. (2012). Methanomassiliicoccus luminyensis gen. nov., sp. nov., a methanogenic archaeon isolated from human faeces. Int. J. Syst. Evol. Microbiol. 62, 1902-1907. doi: 10.1099/ijs.0.033712-0

Faybishenko, B., Birkholzer, J., Sassani, D., and Swift, P. (2016). International Approaches for Nuclear Waste Disposal in Geological Formations: Geological Challenges in Radioactive Waste Isolation-Fifth Worldwide Review. Lawrence Berkeley National Lab, Berkeley, CA United States.

Felicione, F. S., Carney, K. P., Dwight, C. C., Cummings, D. G., and Foulkrod, L. E. (2003). "Gas-generation experiments for long-term storage of TRU wastes at WIPP” in Proceedings of WM03; February 23-27, 2003; Tucson, Arizona, United States.

Hattori, S. (2008). Syntrophic acetate-oxidizing microbes in methanogenic environments. Microbes Environ. 23, 118-127. doi: 10.1264/jsme2.23.118

Hattori, S., Kamagata, Y., Hanada, S., and Shoun, H. (2000). Thermacetogenium phaeum gen. nov., sp. nov., a strictly anaerobic, thermophilic, syntrophic acetate-oxidizing bacterium. Int. J. Syst. Evol. Microbiol. 50, 1601-1609. doi: 10.1099/00207713-50-4-1601

Humphreys, P. N., Laws, A., and Dawson, J. (2010). A Review of Cellulose Degradation and the Fate of Degradation Products Under Repository Conditions. Serco Contractors Report for the Nuclear Decommissioning authority, Harwell, UK.

IAEA (2011). Geological Disopsal of Radioactive Waste. Vienna, Austria: International Atomic Energy Agency.

Jin, Q., and Kirk, M. F. (2018). pH as a primary control in environmental microbiology: 1 thermodynamic perspective. Front. Environ. Sci. 6:21. doi: $10.3389 /$ fenvs.2018.00021

Johnson, D. (2008). The archaeology and technology of early-modern lime burning in the yorkshire dales: developing a clamp kiln model. Ind. Archaeol. Rev. 30, 127-143. doi: 10.1179/174581908X347346

Jones, B. E., Grant, W. D., Duckworth, A. W., and Owenson, G. G. (1998). Microbial diversity of soda lakes. Extremophiles 2, 191-200. doi: 10.1007/ s007920050060
Kotelnikova, S., Macario, A. J., and Pedersen, K. (1998). Methanobacterium subterraneum sp. nov., a new alkaliphilic, eurythermic and halotolerant methanogen isolated from deep granitic groundwater. Int. J. Syst. Bacteriol. 48, 357-367. doi: 10.1099/00207713-48-2-357

Kröninger, L., Deppenmeier, U., and Welte, C. (2014). Experimental evidence of an acetate transporter protein and characterization of acetate activation in aceticlastic methanogenesis of Methanosarcina mazei. FEMS Microbiol. Lett. 359, 147-153. doi: 10.1111/1574-6968.12550

Kyeremeh, I. A., Charles, C. J., Rout, S. P., Laws, A. P., and Humphreys, P. N. (2016). Microbial community evolution is significantly impacted by the use of calcium isosaccharinic acid as an analogue for the products of alkaline cellulose degradation. PLoS One 11:e0165832. doi: 10.1371/journal.pone.0165832

Libert, M., Bildstein, O., Esnault, L., Jullien, M., and Sellier, R. (2011). Molecular hydrogen: an abundant energy source for bacterial activity in nuclear waste repositories. Phys. Chem. Earth 36, 1616-1623. doi: 10.1016/j.pce.2011.10.010

Liu, Y., and Whitman, W. B. (2008). Metabolic, phylogenetic, and ecological diversity of the methanogenic archaea. Ann. N. Y. Acad. Sci. 1125, 171-189. doi: 10.1196/annals.1419.019

Manzoor, S., Schnürer, A., Bongcam-Rudloff, E., and Müller, B. (2018). Genomeguided analysis of Clostridium ultunense and comparative genomics reveal different strategies for acetate oxidation and energy conservation in syntrophic acetate-oxidising bacteria. Genes 9:225. doi: 10.3390/genes9040225

Mathrani, I. M., Boone, D. R., Mah, R. A., Fox, G. E., and Lau, P. P. (1988). Methanohalophilus zhilinae sp. nov., an alkaliphilic, halophilic, methylotrophic methanogen. Int. J. Syst. Bacteriol. 38, 139-142. doi: 10.1099/00207713-38-2-139

Mayes, W. M., Younger, P. L., and Aumônier, J. (2008). Hydrogeochemistry of alkaline steel slag leachates in the UK. Water Air Soil Pollut. 195, 35-50. doi: 10.1007/s11270-008-9725-9

Milodowski, A. E., Shaw, R. P., and Stewart, D. I. (2013). Harpur Hill Site: its geology, evolutionary history and a catalogue of materials present. British Geological Survey, Keyworth, Nottingham, UK.

NDA (2010). Gas Status Report. Harwell, UK: Nuclear Decommissioning Authority. NEA (2014). Updating the NEA International FEP List: Technical Note 1: Identification and Review of Recent Project specific FEP Lists. Paris, France: Nuclear Energy Agency.

Poller, A., Mayer, G., Darcis, M., and Smith, P. (2016). Modelling of Gas Generation in Deep Geological Repositories after Closure. Wettingen, Switzerland: NAGRA.

Rout, S. P., Charles, C. J., Doulgeris, C., McCarthy, A. J., Rooks, D. J., Loughnane, J. P., et al. (2015a). Anoxic biodegradation of isosaccharinic acids at alkaline $\mathrm{pH}$ by Natural Microbial Communities. PLoS One 10:e137682. doi: 10.1371/journal.pone.0137682

Rout, S. P., Charles, C. J., Garratt, E. J., Laws, A. P., Gunn, J., and Humphreys, P. N. (2015b). Evidence of the generation of isosaccharinic acids and their subsequent degradation by local microbial consortia within hyper-alkaline contaminated soils, with relevance to intermediate level radioactive waste disposal. PLoS One 10:e0119164. doi: 10.1371/journal.pone.0119164

Rout, S. P., Radford, J., Laws, A. P., Sweeney, F., Elmekawy, A., Gillie, L. J., et al. (2014). Biodegradation of the alkaline cellulose degradation products generated during radioactive waste disposal. PLoS One 9:e107433. doi: 10.1371/ journal.pone.0107433

Sorokin, D. Y., Abbas, B., Geleijnse, M., Pimenov, N. V., Sukhacheva, M. V., and van Loosdrecht, M. (2015). Methanogenesis at extremely haloalkaline conditions in the soda lakes of Kulunda Steppe (Altai, Russia). FEMS Microbiol. Ecol. 91:fiv016. doi: 10.1093/femsec/fiv016

Sorokin, D. Y., Makarova, K. S., Abbas, B., Ferrer, M., Golyshin, P. N., Galinski, E. A., et al. (2017). Discovery of extremely halophilic, methylreducing euryarchaea provides insights into the evolutionary origin of methanogenesis. Nat. Microbiol. 2:17081. doi: 10.1038/nmicrobiol.2017.81

Summerling, T. (2013). Assessment of Carbon-14 Bearing Gas. Cumbria, UK: LLW Repository Ltd.

Surakasi, V. P., Wani, A. A., Shouche, Y. S., and Ranade, D. R. (2007). Phylogenetic analysis of methanogenic enrichment cultures obtained from Lonar Lake in India: isolation of Methanocalculus sp. and Methanoculleus sp. Microb. Ecol. 54, 697-704. doi: 10.1007/s00248-007-9228-z

Takahashi, S., Tomita, J., Nishioka, K., Hisada, T., and Nishijima, M. (2014). Development of a prokaryotic universal primer for simultaneous analysis of bacteria and archaea using next-generation sequencing. PLoS One 9:e105592. doi: 10.1371/journal.pone.0105592 
Thakker, C. D., and Ranade, D. R. (2002). An alkalophilic Methanosarcina isolated from Lonar crater. Curr. Sci. 82, 455-458.

Westerholm, M., Roos, S., and Schnürer, A. (2010). Syntrophaceticus schinkii gen. nov., sp. nov., an anaerobic, syntrophic acetate-oxidizing bacterium isolated from a mesophilic anaerobic filter. FEMS Microbiol. Lett. 309, 100-104. doi: 10.1111/j.1574-6968.2010.02023.x

Conflict of Interest: The authors declare that the research was conducted in the absence of any commercial or financial relationships that could be construed as a potential conflict of interest. RWM Ltd. had no influence on the design or execution of this study or the interpretation and reporting of the data reported in this paper.

Copyright (c) 2020 Wormald, Rout, Mayes, Gomes and Humphreys. This is an open-access article distributed under the terms of the Creative Commons Attribution License (CC BY). The use, distribution or reproduction in other forums is permitted provided the original author(s) and the copyright owner(s) are credited and that the original publication in this journal is cited, in accordance with accepted academic practice. No use, distribution or reproduction is permitted which does not comply with these terms. 